\title{
Metachronous Medulloblastoma in a Child With Successfully Treated Neuroblastoma: Case Report and Novel Findings of DNA Sequencing
}

\author{
Agda Karina Eterovic, PhDa; Ossama M. Maher, MD² ; Joya Chandra, PhDc; Ken Chen, $\mathrm{PhD}^{\mathrm{d}}$; \\ Jason Huse, $\mathrm{MD}, \mathrm{PhD}^{\mathrm{e}}$; and Wafik Zaky, $\mathrm{MD}^{\mathrm{c}}$
}

\begin{abstract}
Metachronous neoplasms have rarely been reported in patients with neuroblastoma. This report presents the clinical case of a 23-monthold child who was diagnosed with an anaplastic medulloblastoma 5 months after completing treatment for stage IV neuroblastoma. The patient was treated with complete surgical resection and adjuvant chemoradiation followed by maintenance chemotherapy at an outside institution and came to our institution for further management. A pathologic diagnosis and review of both the suprarenal and posterior fossa masses were performed, as well as a genetic analysis of both cerebellar tumor tissue and blood using next-generation gene sequencing. At our institution, the patient was submitted to induction chemotherapy followed by high-dose chemotherapy and autologous stem cell transplantation and remains free of disease 2 years after completion of treatment. Genetic analysis revealed multiple somatic copy number variations with most deleted genes located in 2q37, a region which harbors genes involved in epigenetic regulation and tumor suppression. A homozygous deletion was found in the TSC2 gene, which is a clinically actionable gene, and patients with activating deletions in TSC2 can potentially be eligible for basket clinical trials with mTOR inhibitors. Germline single nucleotide variants were also identified in multiple genes involved in cancer (ALK, FGFR3, FLT3/4, HNF1A, NCOR1, and NOTCH2/3), cancer predisposition (TP53, TSC1, and BRCA1/2), and genes involved in DNA repair ( $M S H 6, P M S 2, P O L E$, and $A T M)$. Metachronous neoplasms are rare and challenging to treat, hence genetic analysis and referral are needed to exclude hereditary cause. DNA sequencing of the tumor and germline can help identify alterations that increase predisposition or can be used to guide treatment decisions on recurrence and when standard options fail.
\end{abstract}

J Natl Compr Canc Netw 2018;16(6):683-691 doi: 10.6004/jncen.2018.7009

Embryonal neoplasms of the central nervous system (CNS) represent nearly one-third of brain tumors in children aged $<3$ years. ${ }^{1,2}$ Medulloblastoma with its different histologic variants belongs to this group, representing up to $20 \%$ of pediatric CNS tumors. Cerebellar neuroblastoma is an extremely uncommon entity of this group with few published reports on primary cerebellar neuroblastoma. ${ }^{3,4}$ A number of second neoplasms have been reported in patients with neuroblastoma, including CNS tumors (gliomas and meningioma), but no prior reports of medulloblastoma. These second primary can-

anstitute for Personalized Cancer Therapy, The University of Texas MD Anderson Cancer Center, Houston, Texas; ${ }^{b}$ Nicklaus Children's Hospital, Pediatric Hematology and Oncology, Miami, Florida; and the Departments of 'Pediatrics, 'Bioinformatics and Computational Biology, and ePathology, The University of Texas MD Anderson Cancer Center, Houston, Texas. Submitted May 27, 2017; accepted for publication January 24, 2018. cers have mostly occurred many years after long-term surveillance. ${ }^{5-7}$ This report presents a case of medulloblastoma in a child 5 months after successful treatment of stage IV neuroblastoma, and discusses the findings in the DNA sequencing results of both the resected posterior fossa tumor and the germline mutations.

\section{Methods}

Approval was obtained from The University of Texas MD Anderson Cancer Center Institutional Review

The authors have disclosed that they have no financial interests, arrangements, affiliations, or commercial interests with the manufacturers of any products discussed in this article or their competitors.

Correspondence: Wafik Zaky, MD, Department of Pediatrics, The University of Texas MD Anderson Cancer Center, 1515 Holcombe Boulevard, Unit 87, Houston, TX 77030. Email: wzaky@mdanderson.org 
Board for this study (Clearing House protocol by Dr. Funda Meric-Bernstam), and informed consent was obtained. Separate consent for the molecular studies and analysis was also obtained. Pathologic diagnosis and review of the suprarenal and posterior fossa masses was performed by members of the Division of Pathology and Laboratory Medicine. Immunohistochemical studies that are pertinent to neuroblastoma and medulloblastoma tumors were used, including CD57 and neurofilaments.

\section{DNA Sequencing and Analysis}

Genomic DNA was quantified by PicoGreen (Invitrogen, Ltd.) and quality was assessed using Genomic DNA ScreenTape for the 2200 TapeStation (Agilent Technologies). Library preparation, targeted capture, and data analysis were completed as previously described. ${ }^{8}$ For data analysis, the T200 targetcapture deep-sequencing data was aligned to human reference assembly hg19 using the Burrows-Wheeler Alignment tool ${ }^{9}$ and duplicated reads were removed using Picard. ${ }^{10}$ Single nucleotide variants and small insertions/deletions were detected using an inhouse-developed analysis pipeline, ${ }^{11}$ which classified variants into 3 categories: somatic, germline, and loss of heterozygosity based on variant allele frequencies in the tumor and the matched normal tissues. Copy number alterations were determined using a previously published algorithm, ${ }^{12}$ which reports gain or loss status of each exon. To understand the potential functional consequence of detected variants, we compared them with the SNP Database, Catalogue of Somatic Mutations in Cancer, ${ }^{13}$ and The Cancer Genome Atlas database, and annotated them using VEP, ${ }^{14}$ ANNOVAR, ${ }^{15}$ CanDrA, ${ }^{16}$ and other programs. Translation consequence of the alteration, such as nonsynonymous, missense, stop-gain, frameshift, and others, follows Sequence Ontology (http:// www.sequenceontology.org). All aberrations that are nonsynonymous were shown. The software used for predicting consequences and clinical implications has been previously described: PolyPhen (the higher the score, the more damaging the aberration), ${ }^{17}$ SIFT (the lower the score, the more deleterious the aberration), ${ }^{18}$ and CanDrA ${ }^{16}$ to identify whether the mutation is the driver versus the passenger.

\section{Case Description}

A 10-month-old girl presented with 2-month history of proptosis and progressive periorbital ecchymosis. She was born full-term via vaginal delivery and has an insignificant past medical history, and her family history was negative for cancer. A CT scan revealed a right retro-orbital mass measuring $2.7 \times 1.2 \times 1.8$ $\mathrm{cm}$. A CT of the abdomen showed a calcified right adrenal mass measuring $6.5 \times 5.5 \times 5.5 \mathrm{~cm}$ with liver metastasis. Evaluation studies for staging including metaiodobenzylguanidine (MIBG) revealed disease at the anterior mediastinum, liver, bone marrow, skull, and third lumber vertebra. Brain MRI revealed disease in the right orbital fossa extending to the middle cranial fossa, with no intracranial or cerebellar disease. The patient underwent fine-needle aspiration biopsy of the orbital mass, and neuroblastoma was diagnosed. A urine catecholamine test was performed initially and reported to be unremarkable; however, upon patient transfer to a tertiary facility with a pediatric oncology floor, this test was repeated and found to be elevated $(91 \mathrm{ng} / \mathrm{mL}$ vs a normal institutional laboratory reference range of 15.7-17.0 $\mathrm{ng} / \mathrm{mL}$ ). Further staging evaluation was performed, including spine MRI and spinal tap, and found to be negative for disease.

Chemotherapy with vincristine, cyclophosphamide, cisplatin, and doxorubicin was initiated. After the first 2 cycles of chemotherapy, the patient underwent disease evaluation. Laparotomy and resection of the right adrenal mass and adjacent lymph nodes were performed, and pathology confirmed the diagnosis of neuroblastoma with poor differentiation and extensive treatment-related changes (necrosis and calcification) (Figure 1A). No NMYC amplification or $1 p$ or $17 q$ deletion were seen, and her karyotype was unremarkable. The patient was classified as having intermediate-risk disease and resumed chemotherapy consisting of vincristine, cyclophosphamide, cisplatin, dacarbazine, ifosfamide, and doxorubicin, followed by 5 maintenance cycles of 13-cis retinoic acid. Surveillance MIBG during maintenance chemotherapy revealed no residual disease.

Five months after completing treatment, the patient presented with repeated vomiting and new onset of difficulty walking after experiencing head trauma. MRI of the brain showed a mass in the right cerebellar hemisphere with hydrocephalus (Figure 1E). Com- 


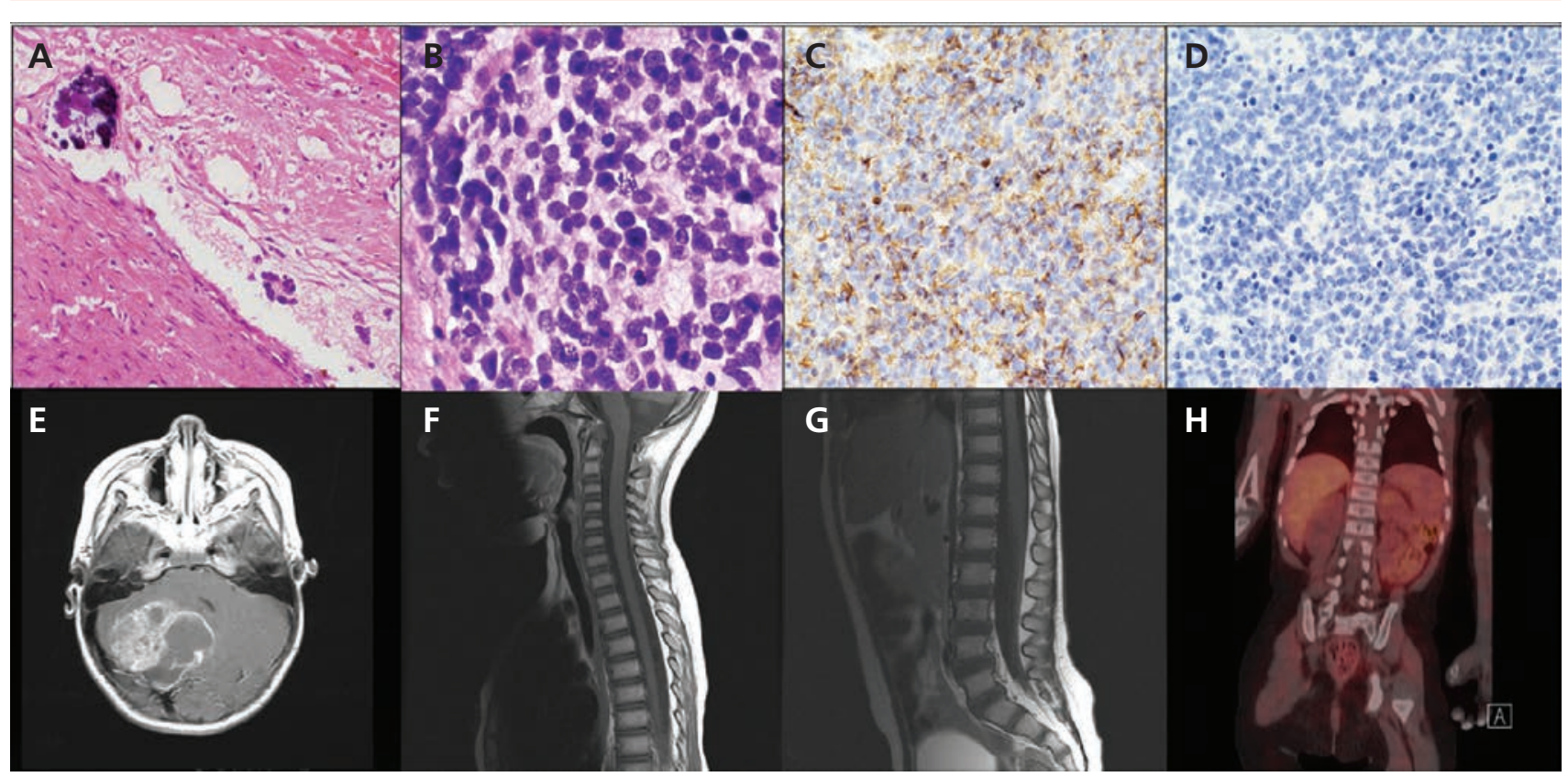

Figure 1. (A) Posttherapy calcification of adrenalectomy and rare viable neuroblastoma cells showing good therapeutic response to adjuvant chemotherapy (hematoxylin-eosin, original magnification $\times 100$ ). (B) Small round blue cell tumor with anaplastic medulloblastoma features in a section of the brain (hematoxylin-eosin, original magnification x400). Immunohistochemical study (C) positive for anti-CD57 and (D) negative for neurofilament (original magnification $\times 100$, for both). (E) Axial T1 MRI of the brain with contrast showing a $5 \times 4-\mathrm{cm}$ enhancing mass in the right cerebellum that is compressing the adjacent structures. MRI of the (F) upper and (G) lower spine showing no evidence of metastatic disease, and (H) metaiodobenzylguanidine scan at restaging workup revealing no evidence of neuroblastoma recurrence.

plete surgical resection of the mass was performed and pathology revealed anaplastic medulloblastoma (Figure 1B). Metastatic workup, including spine MRI, spinal tap, urine catecholamine testing, and MIBG scan, was negative for disease (Figure $1 \mathrm{~F}-\mathrm{H}$ ).

Chemoradiation with vincristine was initiated, and a brain MRI following completion was negative for disease. The treatment was stopped because disseminated fungal infection was suspected after the patient developed fever and neutropenia, and CT of the liver showed some nodularity but blood culture results were negative. Antifungal therapy was initiated for a total of 6 weeks. The treating team decided to decrease treatment intensity and the patient was switched to metronomic therapy with oral cyclophosphamide and topotecan for 2 cycles. The patient came to The University of Texas MD Anderson Cancer Center (MDACC) for a second opinion and further management. A review of the pathology at MDACC agreed with the findings of a small round blue cell tumor, positive CD57 test results, and the absence of neuroblastic differentiation, which indicate the diagnosis of medulloblastoma, anaplastic variant (Figure 1C, D). Considering the prior treatment of neuroblastoma and the incomplete treatment of medulloblastoma, the team decided to proceed with second-line chemotherapy with temozolomide and irinotecan for relapsed medulloblastoma and, if the patient responded well, to follow with high-dose chemotherapy and autologous stem cell transplant (SCT) for curative intent. She was started on temozolomide $\left(150 \mathrm{mg} / \mathrm{m}^{2}\right.$ x 5 days $)$ and irinotecan $\left(50 \mathrm{mg} / \mathrm{m}^{2}\right.$ x 5 days $)$ every 28 days for 5 cycles.

No disease recurrence was seen on end-of-induction imaging and spinal tap, and therefore the patient proceeded with a planned 3 tandem autologous SCT with a conditioning regimen of carboplatin and thiotepa. The patient tolerated the treatment well, and end-of-treatment brain and spine MRI and lumbar puncture revealed no evidence of disease. At time of writing, the patient continues to be in remission from both diseases for $>2$ years posttreatment.

\section{DNA Sequencing and Copy Number Analysis}

A genetic analysis of the medulloblastoma sample was performed using a targeted panel of 263 cancerrelated genes. ${ }^{8}$ Supplemental eTable 1 (available with this article at JNCCN.org) illustrates the genes 
Eterovic et al

in the panel (all exons). Molecular sequencing of the cerebellar tumor tissue did not reveal any relevant, nonsynonymous somatic mutations. The absence of mutations in the CTNNB, SMO, SUFU, and PATCH1 genes suggests a non-WNT, non-SHH type of medulloblastoma.

However, copy number analysis of the cerebellar tumor tissue identified homozygous deletions (H. DEL $\leq 1$ copy) of various genes, including ATG4B, AXIN1, CREBBP, D2HGDH, FBRS, GPC1, GPR35, HDLBP, ING5, KIF1A, PASK, PPP1R7, SNED1, and TSC2, as well as high amplification $(\mathrm{H}$. AMP $\geq 4$ copies) of the TOP 1 and SOX 4 genes (Table 1, Figure 2A). Interestingly, most of the deleted genes were located in chromosome 2 (q37.3) and, less commonly, chromosome 16 (p11-13). Many other focal areas of lower level deletion or amplification were also observed in the cerebellar tumor, suggesting a moderate level of genomic instability (Figure 2B).

Germline DNA from blood was also tested using the same gene panel. Among hundreds of single nucleotide polymorphisms (SNPs) detected, we selected nonsynonymous alterations that are related to cancer (ALK, FGFR3, FLT3/4, HNF1A, NCOR1, and NOTCH2/3), cancer predisposition (TP53, TSC1, and BRCA1/2), and DNA repair
(MSH6, PMS2, POLE, and ATM) (Table 2). On further analysis of the germline data using state of the art literature-based methodology to identify possible damaging, deleterious, and potentially driver mutations, ${ }^{15-18}$ we refined the list of germline SNPs of interest to include FGFR3, FLT3/4, HNF1A, NCOR1, and NOTCH3. Unfortunately, not enough viable tissue was available to perform sequencing of the adrenal tumor.

\section{Discussion}

The occurrence of metachronous neoplasms is rare in children, with only a few reported cases in patients with neuroblastoma, including renal cell carcinoma, epithelioid tumor, and astrocytoma, but not medulloblastoma. ${ }^{19-21}$ Furthermore, cancer survivors are at a higher risk of second cancers compared with the general population. Analyses of 9,432 long-term neuroblastoma survivors in 3 major studies indicated that 96 patients developed second cancers, including carcinomas, soft tissue sarcomas, glioblastomas, meningioma, melanomas, and hematologic malignancies, but none developed medulloblastoma (Table 3). ${ }^{5-7}$ Neuroblastoma and, less commonly, medulloblastoma, have been reported in patients with cancer predisposition syn-

\begin{tabular}{|c|c|c|c|c|c|}
\hline Gene & Copy Change & Gene Copy & Gene Location & Function & Role in Tumorigenesis \\
\hline SOX4 & Amplification & 9.3 & $6 \mathrm{p} 22.3$ & Transcription factors & $\begin{array}{l}\text { Multiple solid tumors, including osteosarcoma, prostate, } \\
\text { and lung }\end{array}$ \\
\hline TOP1 & Amplification & 6 & $20 q 12$ & DNA topoisomerase enzyme & Multiple cancers, including breast, colorectal, and melanoma \\
\hline$A T G 4 B$ & Deletion & 1 & $2 q 37.3$ & Autophagy & Multiple cancers, including breast \\
\hline AXIN1 & Deletion & 0.9 & $16 \mathrm{p} 13.3$ & Tumor suppressor & Medulloblastoma and colorectal and gynecologic cancers \\
\hline CREBBP & Deletion & 0.9 & $16 p 13.3$ & Gene transcription and epigenetic regulation & Multiple cancers, including leukemia, brain, breast, and lung \\
\hline$D 2 H G D H$ & Deletion & 1 & $2 q 37.3$ & $\begin{array}{l}\text { Mitochondrial enzyme and epigenetic } \\
\text { regulation }\end{array}$ & $\mathrm{IDH}$-mutant cancers (gliomas) and prostate cancer \\
\hline FBRS & Deletion & 1 & $16 \mathrm{p} 11.2$ & Fibrogenic lymphokine & Not known \\
\hline GPC1 & Deletion & 1 & $2 q 37.3$ & Membrane proteoglycan & Not known \\
\hline GPR35 & Deletion & 1 & $2 q 37.3$ & G-protein receptor & Gastric and breast cancers \\
\hline$H D L B P$ & Deletion & 1 & $2 q 37.3$ & Protein regulate lipid metabolism & $\begin{array}{l}\text { Involved in breast and prostate cancers, and hepatocellular } \\
\text { carcinoma }\end{array}$ \\
\hline ING5 & Deletion & 1 & $2 q 37.3$ & Tumor suppressor and epigenetic regulator & $\begin{array}{l}\text { Multiple solid tumors, including glioblastoma, lung, and } \\
\text { bladder }\end{array}$ \\
\hline KIF1A & Deletion & 1 & $2 q 37.3$ & $\begin{array}{l}\text { Kinesin family protein and epigenetic } \\
\text { regulation }\end{array}$ & $\begin{array}{l}\text { Multiple solid tumors, including neuroblastoma, breast, and } \\
\text { lung }\end{array}$ \\
\hline PASK & Deletion & 1 & $2 q 37.3$ & $\begin{array}{l}\text { Serine/Threonine kinase and epigenetic } \\
\text { regulator }\end{array}$ & Neuroblastoma and others \\
\hline PPP1R7 & Deletion & 1 & $2 q 37.3$ & $\begin{array}{l}\text { Protein phosphatase and epigenetic } \\
\text { regulator }\end{array}$ & Multiple solid tumors \\
\hline SNED1 & Deletion & 1 & $2 q 37.3$ & Structural protein & Possible role in cancer metastasis \\
\hline TSC2 & Deletion & 0.9 & $16 \mathrm{p} 13.3$ & Tumor suppressor & Medulloblastoma and lung and liver cancers \\
\hline
\end{tabular}



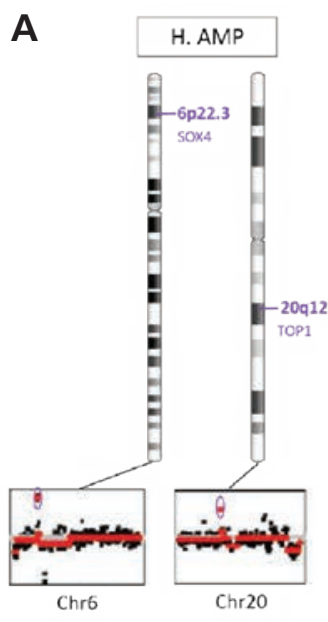

B

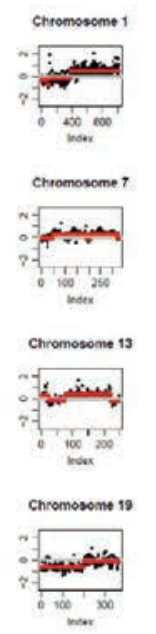

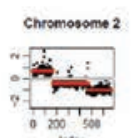
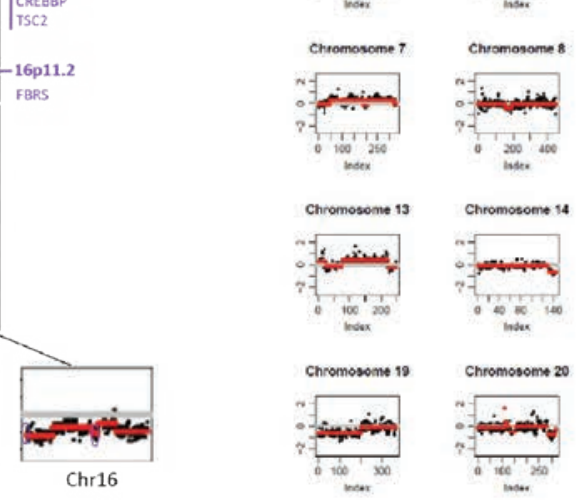
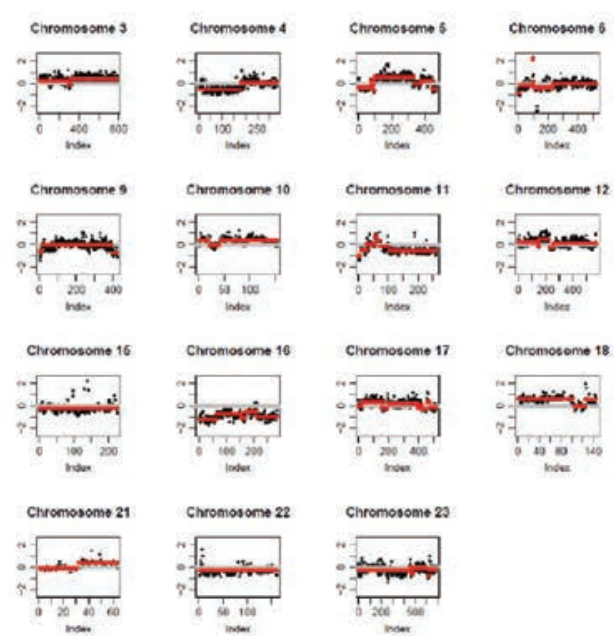

inter
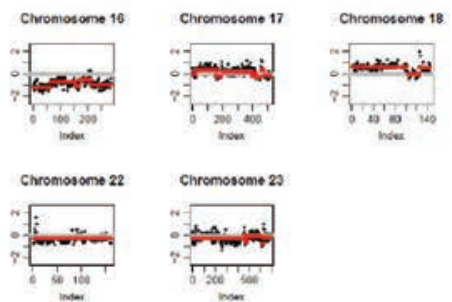

Figure 2. Somatic copy number changes in the medulloblastoma sample. (A) Chromosome location of genes identified with high amplification (H. AMP) and homozygous deletion (H. DEL). (B) Overview of global copy number changes by chromosome. Red lines above and below the gray (normal) line indicate areas of gene amplification and deletion, respectively. Numbers on the $y$ axis represent log-R ratios, and numbers on the $x$ axis represent the gene index.

dromes such as neurofibromatosis type 1 and overgrowth syndromes such as Simpson-Golabi-Behmel syndrome. ${ }^{22-24}$ Our patient did not have clinical stigmata of these conditions and her genetic testing was negative for these syndromes.

Remarkably, the patient had several somatic copy number alterations in the cerebellar tumor, including deletions of ATG4B, AXIN1, CREBBP, D2HGDH, FBRS, GPC1, GPR35, HDLBP, ING5, KIF1A, PASK, PPP1R7, SNED1, and TSC2 genes, as well as amplifications of TOP1 and SOX4 genes (Table 1, Figure 2A). Some of the deleted areas are in genes involved in the epigenetic regulation (D2HGDH, ING5, PASK, PPP1R7, KIF1A, and CREBBP), whereas others act as putative tumor suppressor genes (TSC2, AXIN, KIF1A, and ATG4B). Importantly, deletions of TSC2 are potentially actionable, and on clinical validation, patients harboring these aberrations can be eligible for targeted therapy using mTOR inhibitors. ${ }^{25}$ Therefore, this particular somatic deletion could guide treatment decisions for this patient after recurrence.

Recent studies have shown chromosome 2 microdeletions in several cancers, such as neuroblastoma and breast, lung, and cervical cancers. ${ }^{26-29}$ Strikingly, most of the deletions detected in this patient sample are in genes located in Chr2 q37.3 (Table 1, Figure 2A), an area that harbors many genes involved in skeletal and neuronal development. Although the $2 \mathrm{q} 37.3$ deletion was a somatic event for our patient, it is interesting to mention that the $2 \mathrm{q} 37$ deletion syndrome consists of a germline loss of Chr2 (q37.1, q37.2, q37.3). ${ }^{30}$ Children with this syndrome present with developmental delays and learning disabilities, as well as autism-like symptoms, seizures, and low muscle tone, among other symptoms. However, no germline 2q37 deletion was observed in our patient.

Another intriguing finding was the presence of multiple nonsynonymous germline alterations in genes involved in DNA repair (BRCA 1/2, MSH6, PMS2, POLE, ATM, and ATR) and cancer-predisposing syndromes (TP53 and TSC1). On further analysis, few alterations were found to be clinically relevant; for example, we found POLE to be deleterious, BRCA1 to be damaging, and MSH6 to be both damaging and deleterious. Surprisingly, a group of genes that were found to be damaging, deleterious, and possible drivers includes NOTCH3, FGFR3, FLT3, FLT4, HNF1A, and NCOR1, which have been recognized in literature to play a role in cancer tumorigenesis. Several past studies suggest that genetic alterations in DNA damage response genes can determine the individual risk of developing cancer. ${ }^{29,31}$ MSH6 and PMS2 genes belong to the mismatch repair system and play a basic role in genome integrity maintenance by correcting single base pair mismatches after DNA replication. Mutations of the aforementioned genes have been reported in cancer predisposition syndromes, including Turcot and 
Eterovic et al

\begin{tabular}{|c|c|c|c|c|c|c|c|c|}
\hline Gene Symbol & $\begin{array}{l}\text { Chromosome } \\
\text { Location }\end{array}$ & Nucleotide & AA Position & $\begin{array}{l}\text { AA } \\
\text { Change }\end{array}$ & dbSNP ID & Polyphen 1 & SIFT2 & Candra3 \\
\hline$A L K$ & 2_29444076_C/A & 237 & 79 & $\mathrm{~F} / \mathrm{L}$ & rs1534545 & benign(0) & unknown & unknown \\
\hline ALK & 2_29416572_A/G & 4381 & 1461 & IN & rs1670283 & benign(0) & tolerated(1) & Passenger(0.0020182) \\
\hline ATM & 11_108183167_T/C & 5948 & 1983 & $\mathrm{~N} / \mathrm{S}$ & rs659243 & benign $(0.001)$ & tolerated(0.89) & Passenger(0.097881) \\
\hline ATR & 3_142281612_T/C & 632 & 211 & $\mathrm{M} / \mathrm{T}$ & rs2227928 & benign(0) & tolerated(1) & Passenger(0.7336) \\
\hline ATR & 3_142178144_G/A & 7274 & 2425 & $R / Q$ & rs2229032 & benign $(0.001)$ & tolerated(0.37) & Passenger(0.59435) \\
\hline BRCA1 & 17_41244936_C/T & 2612 & 871 & P/L & rs799917 & benign(0) & tolerated(1) & Passenger(0.51463) \\
\hline BRCA1 & 17_41244000_A/G & 3548 & 1183 & $\mathrm{~K} / \mathrm{R}$ & rs16942 & benign $(0.001)$ & tolerated(1) & Passenger(0.069627) \\
\hline BRCA1 & 17_41244435_A/G & 3113 & 1038 & $E / G$ & rs16941 & possibly_damaging(0.458) & tolerated(0.06) & Passenger(0.74874) \\
\hline BRCA1 & 17_41223094_A/G & 4900 & 1634 & S/G & rs1799966 & probably_damaging(0.925) & deleterious $(0.04)$ & Passenger(0.58022) \\
\hline BRCA2 & 13_32929387_T/C & 7397 & 2466 & V/A & rs169547 & benign(0) & tolerated(1) & Passenger(0.53481) \\
\hline CHEK1 & 11_125525195_A/G & 1411 & 471 & IN & rs506504 & benign $(0.001)$ & tolerated(1) & Passenger(0.067608) \\
\hline FGFR3 & 4_1806629_C/T & 1351 & 451 & $\mathrm{P} / \mathrm{S}$ & rs61735104 & possibly_damaging(0.479) & deleterious $(0.04)$ & Driver(0.81385) \\
\hline FLT3 & 13_28624294_C/T & 680 & 227 & $\mathrm{~T} / \mathrm{M}$ & rs1933437 & possibly_damaging(0.817) & deleterious(0.03) & Driver(0.77501) \\
\hline FLT4 & 5_180046344_C/G & 2670 & 890 & $H / Q$ & rs448012 & benign $(0.32)$ & deleterious $(0.03)$ & Driver(0.66398) \\
\hline HNF1A & 12_121416650_T/G & 79 & 27 & 1/L & rs1169288 & benign $(0.004)$ & deleterious(0.05) & Driver(0.71491) \\
\hline HNF1A & 12_121437221_A/G & 1652 & 551 & L/S & rs1169304 & unknown & deleterious $(0)$ & unknown \\
\hline MSH6 & 2_48025764_G/A & 472 & 158 & $\mathrm{R} / \mathrm{C}$ & rs1800937 & possibly_damaging $(0.88)$ & unknown & unknown \\
\hline NCOR1 & 17_16068463_G/A & 448 & 150 & $\mathrm{G} / \mathrm{R}$ & rs74453660 & probably_damaging(0.957) & deleterious(0.02) & Driver(0.58923) \\
\hline NCOR1 & 17_15973774_A/C & 4218 & 1406 & $L / F$ & rs61753150 & probably_damaging(0.96) & deleterious(0.01) & Driver(0.23452) \\
\hline NOTCH2 & 1_120611554_A/G & 515 & 172 & N/S & rs2794165 & unknown & unknown & unknown \\
\hline NOTCH2 & 1_120611555_A/C & 514 & 172 & $\mathrm{~N} / \mathrm{H}$ & rs2603925 & unknown & unknown & unknown \\
\hline NOTCH2 & 1_120611758_C/T & 313 & 105 & R/W & rs61790276 & unknown & unknown & unknown \\
\hline NOTCH3 & 19_15273335_G/A & 5854 & 1952 & V/M & rs115582213 & probably_damaging(0.936) & deleterious $(0)$ & Driver(0.57713) \\
\hline PMS2 & 7_6026775_A/G & 1621 & 541 & K/E & rs2228006 & benign(0) & tolerated(1) & Passenger(0.25227) \\
\hline PMS2 & 7_6026865_A/G & 1531 & 511 & T/A & rs2228007 & benign( 0 ) & tolerated(1) & Passenger(0.12916) \\
\hline PMS2 & 7_6026988_C/T & 1408 & 470 & $\mathrm{P} / \mathrm{S}$ & rs1805321 & benign $(0.008)$ & tolerated(0.83) & Passenger(0.036327) \\
\hline POLE & 12_133201947_A/G & 458 & 153 & $H / R$ & rs4883544 & benign(0) & tolerated $(0.35)$ & unknown \\
\hline POLE & 12_133220526_A/G & 4187 & 1396 & $\mathrm{~N} / \mathrm{S}$ & rs5744934 & benign $(0.076)$ & deleterious(0.05) & Passenger(0.77497) \\
\hline PRG4 & 1_186273994_G/A & 538 & 180 & R/W & rs2273779 & unknown & unknown & Passenger(0.4551) \\
\hline PRG4 & 1_186275564_G/A & 713 & 238 & $\mathrm{~T} / \mathrm{M}$ & rs12128607 & unknown & unknown & Passenger(0.024218) \\
\hline PRG4 & 1_186276661_T/C & 1810 & 604 & T/A & rs61831150 & unknown & unknown & unknown \\
\hline PRG4 & 1_186277088_C/G & 2237 & 746 & $\mathrm{C} / \mathrm{S}$ & rs68069719 & unknown & unknown & Passenger(0.25328) \\
\hline SMARCA4 & 19_11106600_G/A & 1783 & 595 & $\mathrm{R} / \mathrm{W}$ & rs11672232 & unknown & deleterious $(0)$ & unknown \\
\hline TP53 & 17_7579472_C/G & 215 & 72 & $P / R$ & rs1042522 & benign $(0.145)$ & tolerated $(0.16)$ & Passenger(0.79213) \\
\hline TSC1 & 9_135786904_T/C & 965 & 322 & $\mathrm{M} / \mathrm{T}$ & rs1073123 & benign $(0)$ & tolerated(1) & Passenger(0.29465) \\
\hline
\end{tabular}

All aberrations shown are non-synonymous. The software used for predicting consequences and clinical implications have been previously described: (1) PolyPhen (the higher the score, the more damaging is the aberration), (2) SIFT (the lower the score the more deleterious the aberration), and (3) and CanDrA. Abbreviations: AA, amino acid; dbSNP, database single nucleotide polymorphism.

Lynch syndromes, and are associated with colorectal, brain, and other cancers. ${ }^{32,33}$ Furthermore, other genes belonging to the DNA repair machinery, including ATM and POLE, constitute a network that is crucial for genomic stability, acting as a barrier against tumorigenesis.

Other germline alterations were detected in genes that also seem to play a role in tumorigenesis and tumor progression, but mostly in a somatic context. ${ }^{34-38}$ For example, somatic aberrations in fibroblast growth factor receptor 3 (FGFR3), which is a tyrosine kinase receptor for the FGF ligands, confer a selectable survival advantage in multiple solid tumors. ${ }^{39}$ The FGFR3IIIS is a splice variant that may act as a dominant negative, inhibiting FGFR3- induced growth arrest and differentiation, and has been detected in both medulloblastoma and neuroblastoma. ${ }^{40}$ Another example, the FLT3 gene, which encodes a receptor tyrosine kinase, is a cytokine receptor that regulates hematopoiesis and mutations in this receptor, and can result in acute myeloid leukemia and acute lymphoblastic leukemia. ${ }^{41}$ Treatment with FLT3 ligand induces proliferation and growth in neuroblastoma cell lines, which was significantly inhibited with FLT3 antisense, indicating a role in tumorigenesis. FLT4 is a receptor tyrosine kinase for VEGF-C and VEGF-D ligands, and plays vital role in angiogenesis through activation of AKT and MAPK signaling pathways, which promote proliferation, survival, and migration of endothelial cells, and reg- 
Medulloblastoma in Child With History of Neuroblastoma

\begin{tabular}{|c|c|c|c|c|c|c|}
\hline Study & $\begin{array}{l}\text { Median Age of } \\
\text { SMN Diagnosis } \\
\text { (Range) }\end{array}$ & $\mathbf{N}$ & Result & RT & Chemotherapy & Outcome \\
\hline $\begin{array}{l}\text { Applebaum et al, } \\
2015\end{array}$ & 15 y $(1-46 y)$ & 2,801 & $\begin{array}{l}\text { SEER database analysis from 1973-2006 } \\
34 \text { patients developed a SMN } \\
\text { Diagnosis included renal cell carcinoma } \\
(n=7) \text {, thyroid carcinoma }(n=5) \text {, hematologic } \\
\text { malignancies or lymphoma }(n=10) \text {, sarcoma } \\
(n=7) \text {, melanoma }(n=1) \text {, meningioma }(n=1) \text {, } \\
\text { and other }(n=3)\end{array}$ & $\begin{array}{l}\text { RT in } 25 \% \text { of } \\
\text { patients }\end{array}$ & Multiple regimens & $\begin{array}{l}\text { Cumulative incidence of } \\
\text { SMN at } 30 \text { years for high-risk } \\
\text { patients was } 10.44 \%(95 \% \\
\text { Cl, } 3.98 \%-20.52 \%) \text { vs } 3.57 \% \\
(95 \% \mathrm{Cl}, 1.87 \%-6.12 \%) \\
\text { for non-high-risk patients } \\
(P<.001)\end{array}$ \\
\hline $\begin{array}{l}\text { Applebaum et al, }{ }^{6} \\
2017\end{array}$ & 6.7 y $(9-23.6 y)$ & 5,987 & $\begin{array}{l}\text { INRG database from } 1990-2010 \\
43 \text { patients developed a SMN } \\
\text { Diagnosis included ALL or lymphoma }(n=9) \text {, } \\
\text { AML }(n=10) \text {, sarcoma }(n=12) \text {, carcinoma } \\
(n=6) \text {, and brain tumor }(n=6)\end{array}$ & Not defined & Multiple regimens & $\begin{array}{l}\text { 10-year cumulative incidence } \\
\text { of SMN for high-risk } \\
\text { patients was } 1.8 \% \text { ( } 95 \% \mathrm{Cl} \text {, } \\
1.0 \%-2.6 \%) \text { vs } 0.38 \%(95 \%) \\
\mathrm{Cl}, 0.22 \%-0.94 \%) \text { for low-risk } \\
\text { patients ( } P=.01 \text { ) } \\
\text { High-risk patients had } \\
\text { an almost } 18 \text {-fold higher } \\
\text { incidence of SMN vs } \\
\text { age- and sex-matched } \\
\text { controls (SIR }=17.5 ; 95 \% \mathrm{Cl} \text {, } \\
11.4-25.3)\end{array}$ \\
\hline $\begin{array}{l}\text { Huibregtse } \\
\text { et al,7 } 2016\end{array}$ & 4.4 y $(0.5-37.8 y)$ & 644 & $\begin{array}{l}\text { Multi-institutional retrospective study } \\
\text { between } 1984 \text { to } 2014 \\
19 \text { patients developed a SMN after } \\
\text { treatment with }{ }^{131} \mid-M I B G \\
\text { Diagnosis included ALL }(n=2) \text {, AML }(n=10) \text {, } \\
\text { thyroid carcinoma }(n=2) \text {, sarcoma }(n=2) \text {, } \\
\text { inflammatory myofibroblastic tumor }(n=2) \text {, } \\
\text { and other }(n=1)\end{array}$ & RT in $17 / 19$ patients & Multiple regimens & $\begin{array}{l}\text { Cumulative incidence } \\
\text { of SMN was } 7.6 \%(95 \% \mathrm{Cl} \text {. } \\
4.4-13.0 \%) \text { and } 14.3 \%(95 \% \\
\mathrm{Cl}, 8.3-23.9 \%) \text { at } 5 \text { and } 10 \\
\text { years, respectively }\end{array}$ \\
\hline
\end{tabular}

Abbreviations: ALL, acute lymphoblastic leukemia; AML, acute myeloid leukemia; INRG, International Neuroblastoma Risk Group; MIBG, metaiodobenzylguanidine; RT, radiation therapy; SIR, standardized incidence ratio; SMNs, second malignant neoplasms.

ulates angiogenic sprouting. FLT4 has been found to be overexpressed in tumors, including medulloblastoma, glioblastoma, and neuroblastoma, and confers poor outcome in neuroblastoma. ${ }^{42,43}$ Finally, Notch receptors play an essential role in the regulation of central cellular processes during embryonic and postnatal development, and has been implicated in several cancers, including leukemia, glioma and medulloblastoma. ${ }^{44}$ The Notch pathway prevents neuronal differentiation in the CNS by driving neural stem cell maintenance, and is therefore often implicated in the growth, survival, invasion, and recurrence of brain tumors. Moreover, neuroblastoma has high expression of Notch3, and its downstream-regulated genes have mesenchymal characteristics and are associated with an increased incidence of metastases and poor prognosis. ${ }^{45}$

When this patient presented to MDACC, we were faced with 2 challenges: (1) determining whether the cancer was medulloblastoma versus neuroblastoma, and (2) dealing with the nonstandard treatment approach that was used at the abroad institution. Neuroaxial metastasis of neuroblastoma is not uncommon, and usually occurs at a median of 18 months in high-risk groups with elevated catecholamine. Furthermore, metastatic CNS neuroblastoma frequently appears as a leptomeningeal or interventricular mass, and less commonly as a parenchymal mass (with the frontal lobe the most common location), and not in the cerebellum. In our patient's case, results of the catecholamine test were negative and the tumor was in the cerebellum, and the lack of neurofilament staining and absence of neuroblastic differentiation favored the diagnosis of medulloblastoma. An entity called cerebellar neuroblastoma has been reported rarely in the literature, but there has been no report of its coexistence with extracranial neuroblastoma.

In infant medulloblastoma, high-dose chemotherapy and autologous SCT is a preferred treatment strategy to delay radiation and avoid its deleterious late effect. ${ }^{46}$ Despite complete tumor resection and postoperative radiation therapy in our patient, and because the medulloblastoma was high-risk (due to its anaplastic histologic type and the patient's young age), we proceeded with induction chemotherapy followed by high-dose chemotherapy and autologous SCT to augment the suboptimal dose of radiation and incomplete treatment that was administered at the previous institution.

Regarding management and the therapeutic impact of molecular testing, the patient and parents 
Eterovic et al

were referred to genetic services and the parents were offered genetic testing but decided not to proceed. Our recommendation for follow-up was to perform annual whole-body surveillance imaging with dedicated brain MRI and blood counts. Regarding treatment, future target agents to be considered in the event of recurrence include PARP inhibitors, with literature supporting their use in tumors with DNA damage repair genes alterations (POLE, MSH6, BRCA1/2). ${ }^{47}$ Recently, PD-L1 inhibitors were postulated to be efficacious in treating patients with cancer with mismatch gene repair mutations (MSH6) and/or hypermutation. ${ }^{48}$ This is in addition to other potential targets, such as mTOR inhibition (for tumors with TSC2 deletion). ${ }^{25}$

\section{Conclusions}

Metachronous neoplasms are rare and challenging to treat; hence, genetic testing and referral are needed to exclude familial cancer syndromes and to aid in treatment planning. In addition, DNA sequencing of the tumor can help to identify actionable somatic alterations that could guide treatment decisions when standard treatment fail upon recurrence.

\section{Acknowledgments}

The genetic analysis presented in this case reported was supported by the Khalifa Foundation and The Institute for Personalized Cancer Therapy (IPCT-MDACC). The patient was enrolled in the IPCT Clearing House protocol led by Dr. Funda Meric-Bernstam.

\section{References}

1. Louis DN, Perry A, Reifenberger G, et al. The 2016 World Health Organization Classification of Tumors of the Central Nervous System: a summary. Acta Neuropathol 2016;131:803-820.

2. Ostrom QT, Gittleman H, Farah P, et al. CBTRUS statistical report: primary brain and central nervous system tumors diagnosed in the United States in 2006-2010. Neuro Oncol 2013;15(Suppl 2):ii1-56.

3. Pearl GS, Takei Y. Cerebellar "neuroblastoma": nosology as it relates to medulloblastoma. Cancer 1981;47:772-779.

4. Yagishita S, Itoh Y, Chiba Y, et al. Cerebellar neuroblastoma. A light and ultrastructural study. Acta Neuropathol 1980;50:139-142.

5. Applebaum MA, Henderson TO, Lee SM, et al. Second malignancies in patients with neuroblastoma: the effects of risk-based therapy. Pediatr Blood Cancer 2015;62:128-133.

6. Applebaum MA, Vaksman Z, Lee SM, et al. Neuroblastoma survivors are at increased risk for second malignancies: a report from the International Neuroblastoma Risk Group Project. Eur J Cancer 2017;72:177-185.

7. Huibregtse KE, Vo KT, DuBois SG, et al. Incidence and risk factors for secondary malignancy in patients with neuroblastoma after treatment with (131)I-metaiodobenzylguanidine. Eur J Cancer 2016;66:144-152.

8. Chen $\mathrm{K}$, Meric-Bernstam F, Zhao $\mathrm{H}$, et al. Clinical actionability enhanced through deep targeted sequencing of solid tumors. Clin Chem 2015;61:544-553.

9. Li H, Durbin R. Fast and accurate short read alignment with BurrowsWheeler transform. Bioinformatics 2009;25:1754-1760.

10. DePristo MA, Banks E, Poplin R, et al. A framework for variation discovery and genotyping using next-generation DNA sequencing data. Nat Genet 2011;43:491-498.

11. Zhou W, Chen $\mathrm{T}$, Zhao $\mathrm{H}$, et al. Bias from removing read duplication in ultra-deep sequencing experiments. Bioinformatics 2014;30:1073-1080.

12. Lonigro RJ, Grasso CS, Robinson DR, et al. Detection of somatic copy number alterations in cancer using targeted exome capture sequencing. Neoplasia 2011;13:1019-1025.

13. Bamford S, Dawson E, Forbes $S$, et al. The COSMIC (Catalogue of Somatic Mutations in Cancer) database and website. Br J Cancer 2004;91:355-358.

14. McLaren W, Pritchard B, Rios D, et al. Deriving the consequences of genomic variants with the Ensembl API and SNP Effect Predictor. Bioinformatics 2010;26:2069-2070.

15. Wang K, Li M, Hakonarson H. ANNOVAR: functional annotation of genetic variants from high-throughput sequencing data. Nucleic Acids Res 2010;38:e164.

16. Mao $\mathrm{Y}$, Chen $\mathrm{H}$, Liang $\mathrm{H}$, et al. CanDrA: cancer-specific driver missense mutation annotation with optimized features. PLoS One 2013;8:e77945.

17. Ramensky V, Bork P, Sunyaev S. Human non-synonymous SNPs: server and survey. Nucleic Acids Res 2002;30:3894-3900.
18. Kumar P, Henikoff $\mathrm{S}, \mathrm{Ng}$ PC. Predicting the effects of coding nonsynonymous variants on protein function using the SIFT algorithm. Nat Protoc 2009;4:1073-1081.

19. Kato K, Ijiri R, Tanaka $Y$, et al., Metachronous renal cell carcinoma in a child cured of neuroblastoma. Med Pediatr Oncol 1999;33:432-433.

20. Tanaka M, Kato K, Gomi K, et al. Perivascular epithelioid cell tumor with SFPQ/PSF-TFE3 gene fusion in a patient with advanced neuroblastoma. Am J Surg Pathol 2009;33:1416-1420.

21. Krieger JN, Chasko SB, Keuhnelian JG. Paratesticular neuroblastoma associated with subependymal giant cell astrocytoma. J Urol 1980;124:736738.

22. Jongmans MC, Loeffen JL, Waanders E, et al. Recognition of genetic predisposition in pediatric cancer patients: an easy-to-use selection tool. Eur J Med Genet 2016;59:116-125.

23. Thomas M, Enciso V, Stratton R, et al. Metastatic medulloblastoma in an adolescent with Simpson-Golabi-Behmel syndrome. Am J Med Genet A 2012;158A:2534-2536.

24. Varan A, Sen H, Aydin B, et al. Neurofibromatosis type 1 and malignancy in childhood. Clin Genet 2016;89:341-345.

25. Huynh H, Hao HX, Chan SL, et al. Loss of tuberous sclerosis complex 2 (TSC2) is frequent in hepatocellular carcinoma and predicts response to mTORC1 inhibitor everolimus. Mol Cancer Ther 2015;14:1224-1235.

26. Takita J, Yang HW, Chen YY, et al. Allelic imbalance on chromosome $2 \mathrm{q}$ and alterations of the caspase 8 gene in neuroblastoma. Oncogene 2001;20:4424-4432.

27. Piao Z, Lee KS, Kim H, et al. Identification of novel deletion regions on chromosome arms $2 \mathrm{q}$ and $6 \mathrm{p}$ in breast carcinomas by amplotype analysis. Genes Chromosomes Cancer 2001;30:113-122.

28. Narayan G, Pulido HA, Koul S, et al. Genetic analysis identifies putative tumor suppressor sites at 2q35-q36.1 and 2q36.3-q37.1 involved in cervical cancer progression. Oncogene 2003;22:3489-3499.

29. Rube CE, Fricke A, Schneider R, et al. DNA repair alterations in children with pediatric malignancies: novel opportunities to identify patients at risk for high-grade toxicities. Int J Radiat Oncol Biol Phys 2010;78:359-369.

30. Falk RE, Casas KA. Chromosome $2 \mathrm{q} 37$ deletion: clinical and molecular aspects. Am J Med Genet C Semin Med Genet 2007;145C:357-371.

31. Sijmons RH, Hofstra RM. Review: clinical aspects of hereditary DNA mismatch repair gene mutations. DNA Repair (Amst) 2016;38:155-162.

32. Lindsay H, Jubran RF, Wang L, et al. Simultaneous colonic adenocarcinoma and medulloblastoma in a 12-year-old with biallelic deletions in PMS2. J Pediatr 2013;163:601-603.

33. Scott RH, Mansour S, Pritchard-Jones K, et al. Medulloblastoma, acute myelocytic leukemia and colonic carcinomas in a child with biallelic MSH6 mutations. Nat Clin Pract Oncol 2007;4:130-134.

34. Privalsky ML. The role of corepressors in transcriptional regulation by nuclear hormone receptors. Annu Rev Physiol 2004;66:315-360. 
35. Heldring $\mathrm{N}$, Nyman U, Lonnerberg P, et al. NCoR controls glioblastoma tumor cell characteristics. Neuro Oncol 2014;16:241-249.

36. Pugh TJ, Weeraratne SD, Archer TC, et al. Medulloblastoma exome sequencing uncovers subtype-specific somatic mutations. Nature 2012;488:106-110.

37. Bluteau $\mathrm{O}$, Jeannot $\mathrm{E}$, Bioulac-Sage $\mathrm{P}$, et al. Bi-allelic inactivation of TCF1 in hepatic adenomas. Nat Genet 2002;32:312-315.

38. Rebouissou S, Vasiliu V, Thomas C, et al. Germline hepatocyte nuclear factor 1alpha and 1beta mutations in renal cell carcinomas. Hum Mol Genet 2005;14:603-614

39. Kelleher FC, O'Sullivan H, Smyth E, et al. Fibroblast growth factor receptors, developmental corruption and malignant disease. Carcinogenesis 2013;34:2198-2205.

40. Sturla LM, Merrick AE, Burchill SA. FGFR3IIIS: a novel soluble FGFR3 spliced variant that modulates growth is frequently expressed in tumour cells. Br J Cancer 2003;89:1276-1284.

41. Frohling S, Scholl C, Gilliland DG, Levine RL. Genetics of myeloid malignancies: pathogenetic and clinical implications. J Clin Oncol 2005;23:6285-6295.
42. Eggert A, Ikegaki N, Kwiatkowski J, et al. High-level expression of angiogenic factors is associated with advanced tumor stage in human neuroblastomas. Clin Cancer Res 2000;6:1900-1908.

43. Huber H, Eggert A, Janss AJ, et al. Angiogenic profile of childhood primitive neuroectodermal brain tumours/medulloblastomas. Eur J Cancer 2001;37:2064-2072.

44. Teodorczyk M, Schmidt MH. Notching on cancer's door: notch signaling in brain tumors. Front Oncol 2014;4:341.

45. van Nes J, Chan A, van Groningen $\mathrm{T}$, et al. A NOTCH 3 transcriptional module induces cell motility in neuroblastoma. Clin Cancer Res 2013;19:3485-3494

46. Cohen BH, Geyer JR, Miller DC, et al. Pilot study of intensive chemotherapy with peripheral hematopoietic cell support for children less than 3 years of age with malignant brain tumors, the CCG-99703 phase I/II study. A report from the Children's Oncology Group. Pediatr Neurol 2015;53:31-46.

47. Pihlak R, Valle JW, McNamara MG. Germline mutations in pancreatic cancer and potential new therapeutic options. Oncotarget 2017;8:7324073257.

48. Viale G, Trapani D, Curigliano G. Mismatch repair deficiency as a predictive biomarker for immunotherapy efficacy. Biomed Res Int 2017;2017:4719194

\section{See JNCCN.org for supplemental online content.}

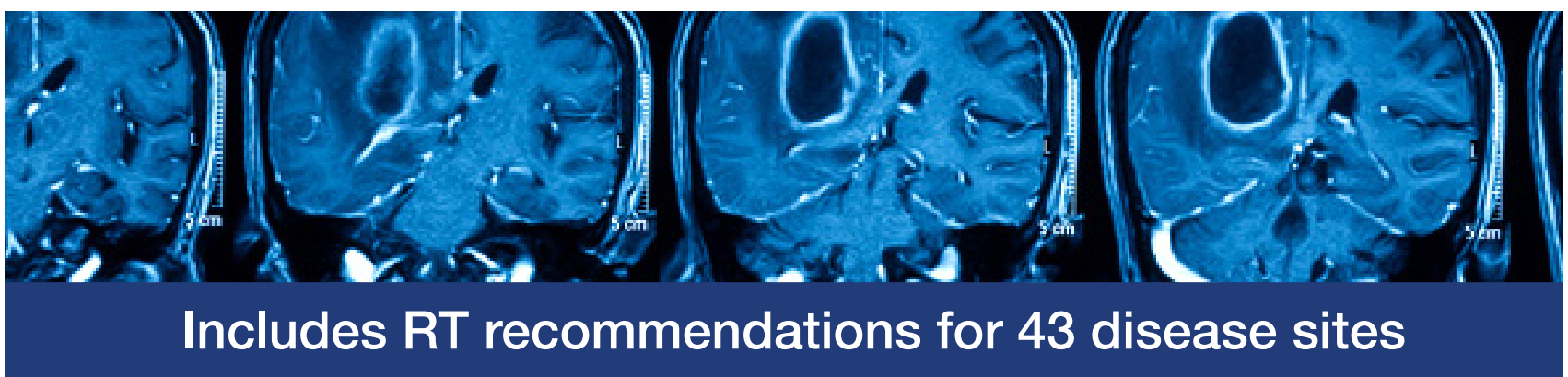

\section{NCCN Radiation Therapy Compendium ${ }^{\mathrm{TM}}$}

The NCCN Radiation Therapy Compendium ${ }^{\mathrm{TM}}$ is designed to support decision-making around the use of radiation therapy in patients with cancer. The radiation therapy recommendations contained in the Compendium are derived directly from the library of NCCN Clinical Practice Guidelines in Oncology (NCCN Guidelines ${ }^{\circledR}$ ), which document evidence-based, consensusdriven management to ensure that all patients receive care most likely to lead to optimal outcomes.

\section{Subscribe and learn more at: NCCN.org/RTcompendium}

